\title{
LEGISLAÇÃO EM SAÚDE: UM ESTUDO SOBRE A INICIATIVA DE PROJETOS DE LEI NO ESTADO DO ACRE
}

Health legislation: a study on legislative bill initiatives in the Brazilian state of Acre

${ }^{1}$ Faculdade de Saúde Pública, Universidade de São Paulo. São Paulo/SP, Brasil.

2 Universidade Federal do Acre. Rio Branco/AC, Brasil.

Correspondência: Luci Maria Teston.E-mail: Iuci_teston@hotmail.com.

Recebido em: 29/04/2014. Revisado em: 04/08/2014. Aprovado em: 11/08/2014. 


\section{RESUMO}

$\mathrm{O}$ artigo analisa as atuações dos poderes Executivo e Legislativo no Estado do Acre quanto à formulação de propostas políticas para a saúde a partir de 1999, comparando duas legislaturas. Parte-se do princípio de que o Executivo dispõe de amplo poder de agenda, o qual permite definir temas essenciais a serem apreciados pelo Legislativo, bem como determinar os passos e a sequência de procedimentos a serem seguidos ao longo do processo decisório. $\mathrm{O}$ estudo foi descritivo e realizado a partir de consulta a documentos da Assembleia Legislativa do Estado do Acre com acesso público. Foram identificados os projetos de lei aprovados pela Assembleia, sendo analisados por autoria, tempo de tramitação e natureza, considerando-se o contexto político-institucional. Das 93 matérias de autoria do Legislativo aprovadas entre 1999 a 2002, $20,4 \%$ trataram de temas relacionados à saúde, em especial a medicamentos, vacinas, insumos e produtos para a saúde. No período seguinte (2003-2006), das 294 proposições aprovadas, $6,8 \%$ estiveram relacionadas à saúde, envolvendo principalmente políticas, planos, programas e projetos. O estudo sugere que houve, entre os dois períodos analisados, uma mudança na natureza dos projetos de autoria do Legislativo aprovados. Os parlamentares, na segunda legislatura, fizeram uso de uma agenda leve, ao priorizarem questões honoríficas e simbólicas.

\section{Palavras-Chave}

Poder Legislativo; Poder Executivo; Legislação Sanitária, Políticas em Saúde.

\section{ABSTRACT}

This article analyzes the actions of the Executive and Legislative Powers of the Brazilian state of Acre in terms of the formulation of health proposals that have been implemented since 1999. Two legislatures are compared. It begins with the principle that the Executive Branch possesses significant agenda-setting power. This power allows this branch to define essential topics to be raised by the Legislative and also to define the steps and the sequence of procedures to be followed in the decision-making process. This descriptive study was performed using publicly available documents from the Acre State Legislative Assembly in Brazil. The bills approved by the Assembly were identified and then organized by author as per their processing time and topic. The political-institutional context was also considered. Out of the 93 topics authored by the Legislative and approved between 1999 and 2002, 20.4\% involved health - particularly medications, vaccines, medical supplies, and healthcare products. During the next period (2003-2006), 6.8\% of the 294 proposals that were approved involved health - particularly policies, plans, programs, and projects. The study suggests that there was a change in the nature of the projects approved by the Legislative between the periods analyzed. In the second legislature, lawmakers gave preference to a light agenda to prioritize honorific and symbolic issues.

\section{Keywords}

Executive Power; Health Legislation; Legislative Power; Public Health Policies. 


\section{Introdução}

A partir da Constituição Federal de 1988 (CF/88) o Executivo assumiu um importante papel na questão legislativa, passando a exercer considerável influência

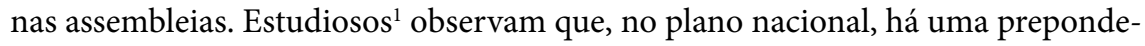
rância legislativa do Executivo explicada pelo amplo poder de agenda dado pela Constituição de 1988 à Presidência da República.

Esse poder serve para encurtar os prazos de tramitação das matérias, por meio do recurso aos pedidos de urgência, e para que não sejam aprovadas propostas indesejáveis (por meio da exclusividade de iniciativa do Executivo em matérias tributárias e orçamentárias). Além disso, há a possibilidade de serem utilizadas as Medidas Provisórias. Sem contar, evidentemente, com os recursos que não são legislativos, resultado do controle exercido sobre o acesso aos postos de governo. Os partidos também são considerados atores estratégicos, com poderes de agenda derivados das regras que estruturam o Legislativo, em especial as lideranças partidárias, que desempenham importante papel na garantia da disciplina das bancadas na Câmara dos Deputados.

Nesse sentido, no plano nacional, conforme entendimento de Abranches ${ }^{2}$, observa-se um Executivo organizado com base em grandes coalizões, que seguem uma lógica partidária e regional e em cuja articulação o presidente exerce um papel de destaque. $\mathrm{O}$ autor entende que a frequência das coalizões reflete a fragmentação partidário-eleitoral - que, por sua vez, tem como base as diferenças socioculturais e regionais presentes na sociedade brasileira.

No período posterior à $\mathrm{CF} / 88$, o comportamento do Legislativo torna-se relativamente mais previsível e cooperativo com o governo. O presidente passa a se tornar um maximizador de agenda, já que ele quer ser percebido como competente e, por isso, precisa de um Congresso cooperativo ${ }^{3}$. Essa influência se dá não apenas em nível nacional, mas também em grande parte dos estados brasileiros.

Um governador com amplos poderes legislativos pode ditar a agenda de trabalhos na Assembleia e, consequentemente, induzir os parlamentares à cooperação, formando, no sentido dado por $\mathrm{Abrú}_{\mathrm{cio}}{ }^{4}$, um "sistema político ultrapresidencialista”. Para que o ultrapresidencialismo seja estabelecido com toda a sua eficácia, é necessário ao governador obter ampla e sólida maioria na Assembleia, tanto para

${ }^{1}$ FIGUEIREDO, Argelina Cheibub. LIMONGI, Fernando. Executivo e Legislativo na nova ordem constitucional. 2. ed. Rio de Janeiro: Ed. FGV, 2001.

${ }^{2}$ ABRANCHES, Sérgio Henrique H. de. Presidencialismo de coalizão: o dilema institucional brasileiro. Dados Rev. Ciênc Soc., v. 31, p. 5-34, 1988.

${ }^{3}$ SANTOS, Fabiano. O Poder Legislativo no Presidencialismo de coalizão. Belo Horizonte: Ed. da UFMG; Rio de Janeiro: IUPERJ, 2003.

${ }^{4}$ ABRUCIO, Fernando Luiz. Os barões da federação: os governadores e a redemocratização brasileira. 2. ed. São Paulo: Hucitec, 2002. 
eliminar sua função de checks and balances como para controlar o processo decisório de forma mais ampla.

Estudos ressaltam uma importante variedade de experiências políticas estaduais em termos de relações entre o Executivo e o Legislativo, representadas por meio da produção legal e da organização interna das assembleias. Pesquisas realizadas junto às Assembleias Legislativas de Minas Gerais ${ }^{5}$, Rio de Janeiro ${ }^{6}$, Espírito Santo ${ }^{7}$ e São Paulo ${ }^{8}$ confirmaram essa variedade.

Entretanto, essas pesquisas geralmente se concentram no Centro-Sul do país, daí a importância de se conhecer a realidade de estados do Norte, em especial quanto à produção legislativa em saúde. Os direitos universais de cidadania para a saúde estão consagrados na Constituição Federal de 1988. No artigo 196, caput, ficou estabelecido que a saúde "é direito de todos e dever do Estado, garantido mediante políticas sociais e econômicas que visem à redução do risco de doença e de outros agravos e ao acesso universal e igualitário às ações e serviços para sua promoção, proteção e recuperação"s.

O Legislativo é um poder que formula políticas públicas, inclusive sanitárias. A ele cabem as atividades de legislar e fiscalizar os demais poderes, podendo, atipicamente, administrar e julgar ${ }^{10}$. Nessa perspectiva, pretende-se analisar as atuações dos poderes Executivo e Legislativo no Estado do Acre quanto à formulação de propostas políticas para a saúde, a partir da comparação entre duas legislaturas.

O período do estudo abrange o primeiro mandato do governador Jorge Viana no comando do Executivo estadual (1999-2002), bem como os quatro anos seguintes (2003-2006), nos quais se manteve no governo por meio da reeleição.

\footnotetext{
${ }^{5}$ ANASTASIA, Fátima. Transformando o Legislativo: a experiência da Assembléia Legislativa de Minas Gerais. In: SANTOS, Fabiano (Org.). O Poder Legislativo nos Estados: diversidade e convergência. Rio de Janeiro: Fundação Getúlio Vargas, 2001. p. 23-83.

${ }^{6}$ SANTOS, Fabiano. A dinâmica legislativa no Estado do Rio de Janeiro: análise de uma legislatura. In: SANTOS, Fabiano (Org.). O Poder Legislativo nos Estados: diversidade e convergência. Rio de Janeiro: Fundação Getúlio Vargas, 2001. p. 163-187.

${ }^{7}$ DOMINGUES, Mauro Petersem. Espírito Santo: produção legal e relações entre os poderes Executivo e Legislativo entre 1995 e 1998. In: SANTOS, Fabiano (Org.). O Poder Legislativo nos Estados: diversidade e convergência. Rio de Janeiro: Fundação Getúlio Vargas, 2001. p. 85-111.

${ }^{8}$ ABRUCIO, F. L.; TEIXEIRA, M. A. C.; COSTA, V. M. F. O papel institucional da Assembléia Legislativa paulista: 1995 a 1998. In: SANTOS, Fabiano (Org.). O Poder Legislativo nos Estados: diversidade e convergência. Rio de Janeiro: Fundação Getúlio Vargas, 2001. p. 219-246.

${ }^{9}$ Entre os anos 1980 e 1990, o Estado brasileiro viu-se na necessidade de redimensionar o seu papel. Em relação à política de saúde, optou pela ampliação da participação democrática e da garantia dos direitos de cidadania, mediante a conformação de um sistema de saúde com características universalizantes, de cunho igualitarista, sustentado pela ideia de justiça social. (VIANA, Ana Luiza d’Ávila et al. Política de saúde e eqüidade. São Paulo em Perspectiva, São Paulo, v. 17, n. 1, p. 58-68. http://dx.doi.org/10.1590/S0102-88392003000100007).

${ }^{10}$ Segundo Baptista e Machado (2007), a atividade legislativa é a que mais se sobressai e também a que mais é veiculada na mídia em geral. BAPTISTA, Tatiana W. de Faria; MACHADO, Cristiani Vieira. O Legislativo e a Saúde no Brasil. In: MATTA, Gustavo Corrêa; PONTES, Ana Lúcia de Moura (Orgs.). Políticas de saúde: organização e operacionalização do sistema único de saúde. Rio de Janeiro: EPSJV; Fiocruz, 2007. p. 81-113.
} 


\section{Método}

A análise das atuações dos poderes Executivo e Legislativo no Acre, quanto à formulação de propostas políticas para a saúde, foi realizada por meio de estudo descritivo a partir de consulta a documentos da Assembleia Legislativa do estado com acesso público. Foi identificada a produção de leis ordinárias em saúde, sendo contemplados na pesquisa os projetos de lei aprovados pela Assembleia e sancionados pelo governador. Os projetos de lei complementar não foram considerados nesta análise, tendo em vista sua baixa incidência. Durante o período, não foram identificadas medidas provisórias. Demais espécies normativas foram excluídas por serem proposições que não necessitam de sanção governamental.

Adotou-se como marco inicial o ano de 1999 porque foi o início de um novo ciclo político no estado, a partir da conquista do Executivo estadual por partidos que representavam a mudança em relação aos moldes políticos anteriores. O período abrange dois mandatos estaduais, com o término da análise em 2006.

Foram identificados e analisados os 810 projetos de lei apresentados no período. Para a mensuração da atuação de cada poder, avaliou-se o percentual de projetos de lei aprovados em comparação com o total de proposições enviadas para apreciação e o tempo de tramitação, com cruzamento de informações. Para a elucidação da questão da legislação em saúde, foi analisada a natureza das proposições apresentadas, sendo definidas as seguintes categorias para a classificação, adaptadas de Santos ${ }^{11}$; Abrucio, Teixeira e Costa ${ }^{12}$ :

- Administrativas: relacionadas com a administração pública, gestão de negócios públicos ou particulares. São abordados temas como criação de órgãos, alterações em dispositivos legais e autorizações em geral;

- De agricultura/pecuária: assuntos que envolvem políticas públicas de incentivo à agropecuária;

- De cidadania: dizem respeito às políticas de promoção de direitos de minorias, direitos do consumidor e participação política;

- Simbólicas: são as declarações de utilidade pública, tombamento de construções, instituição de dias, semanas e prêmios;

- Culturais/científicas/tecnológicas: relacionadas à promoção e ao apoio a atividades culturais, de lazer, científicas e tecnológicas;

- Ecológicas: tratam da política ambiental e da preservação do meio ambiente;

- Econômicas: compreendem a regulamentação de atividades econômicas, a gestão do patrimônio público, a abertura de crédito especial, o pagamento de dívidas e as políticas de incentivo econômico a empresas;

\footnotetext{
${ }^{11}$ SANTOS, Fabiano. A dinâmica legislativa no Estado do Rio de Janeiro: análise de uma legislatura, cit., p. $163-187$.

${ }^{12}$ ABRUCIO, F. L.; TEIXEIRA, M. A. C.; COSTA, V. M. F. op. cit., p. 219-246.
} 
- De fiscalização: são os mecanismos para o maior controle das atividades da administração pública e privada;

- Do funcionalismo: enquadram-se as iniciativas voltadas para benefícios, gratificações, abertura de concursos públicos, planos de cargos e salários, alterações estatutárias, entre outras;

- Honoríficas: correspondem às homenagens (concessões de títulos de cidadão acreano);

- Orçamentárias/financeiras: tratam da política financeira e orçamentária;

- De segurança: relacionadas com a polícia, presídios, segurança no trânsito e em instituições, programa de apoio às vítimas etc.;

- Sociais: são as políticas voltadas para a educação, saúde, saneamento, população indígena, habitação, transporte e bem-estar.

Os projetos de lei identificados com a temática da saúde fazem parte das proposições classificadas como "sociais" e foram analisados separadamente, a partir das seguintes categorias ${ }^{13}$ :

- Administração e planejamento;

- Alimentação e nutrição;

- Medicamentos, vacinas, insumos, produtos para a saúde;

- Políticas, planos, programas e projetos;

- Trabalho em saúde (profissões/profissionais);

- Saúde bucal;

- Sistema Único de Saúde (SUS);

- Saúde nos grupos populacionais específicos;

- Criança e adolescente;

- Mulher;

- Pessoa com deficiência;

- DST e Aids;

- Câncer.

\footnotetext{
${ }^{13} \mathrm{~A}$ classificação das proposições sobre as matérias de saúde teve como referência os estudos de Bem (BEM, Pricken de. Observatório da Saúde no Legislativo: as proposições em saúde no âmbito do Congresso Nacional (2011- 2012). Universidade de Brasília (UnB): Tempus-Actas de Saúde Coletiva, v. 7, n. 1, p. 107-114, 2013) e de Vasconcelos (VASCONCELOS, Wagner R. Manso de. Observatório da saúde no legislativo: informação e comunicação a serviço da participação social em saúde. 2009. Dissertacao (Mestrado), Universidade de Brasília, Brasília, 2009), que fizeram uso das categorias definidas para o Observatório da Saúde no Legislativo.
} 
É importante esclarecer que, em função da utilização de documentos de acesso livre e de domínio público, os dados prescindiram de avaliação de Comitê de Ética em Pesquisa.

\section{Resultados}

\section{Processo Decisório na Assembleia Legislativa}

Como resultado das eleições de 1998, Jorge Viana (PT) é eleito governador do Acre por meio da união de partidos (PDT, PT, PSL, PPS, PSB, PSDB, PT do B, PC do B, PV, PMN, PL e PTB) com atuação no estado, que ficou conhecida como Frente Popular do Acre (FPA). No Legislativo estadual, 50,0\% das vagas são ocupadas por parlamentares eleitos pela FPA. Portanto, em tese, o chefe do Executivo tem o apoio de 12 dos 24 parlamentares.

Passados os quatro primeiros anos à frente do Executivo estadual, Jorge Viana (PT) é reeleito pela FPA, agora com nova configuração (PT, PV, PT do B, PMN, PC do B, PL e PSDC). Na Assembleia, como resultado das eleições de 2002, os partidos que integraram a Frente conquistam $54,0 \%$ das cadeiras - significando, assim, melhores condições de governabilidade para o chefe do Executivo se comparadas com a legislatura anterior.

Em relação à distribuição de cargos na Mesa Diretora, a presidência da Casa esteve sob o comando de partido da base aliada ao governador nas duas legislaturas analisadas (PMN). Quanto às Comissões, tanto a Presidência da Comissão de Constituição e Justiça (CCJ) quanto a da Comissão de Finanças e Tributação (CFT) foram ocupadas por partidos que integravam a FPA nos dois períodos. A CCJ, que analisa a constitucionalidade dos projetos de lei apresentados, e a CFT, que avalia qualquer proposição que tenha impacto fiscal, podem ser consideradas as mais importantes comissões nos legislativos estaduais. Nelas, é recorrente que o presidente avoque a relatoria da matéria para si e se utilize dessa posição para agir estrategicamente, fustigando ou defendendo o Executivo.

Considerando-se esse desenho institucional, procurou-se analisar a produção legislativa. A partir de tais dados, observou-se um Legislativo propositor de projetos, mas também um Executivo que, igualmente, desempenhou seu poder de agenda, com alta proporção de projetos aprovados no período de 1999 a 2006 (Gráfico 1).

Entre os anos de 1999 a 2002, o Executivo aprovou 123 (91,11\%) dos 135 projetos apresentados. Já no mandato seguinte, conseguiu aprovar $99(98,01 \%)$ das 101 proposições apresentadas. Quanto ao Legislativo, de 1999 a 2002 foram aprovados $93(51,95 \%)$ dos 179 projetos e, na legislatura seguinte, houve a aprovação de $294(74,43 \%)$ dos 395 projetos apresentados. 


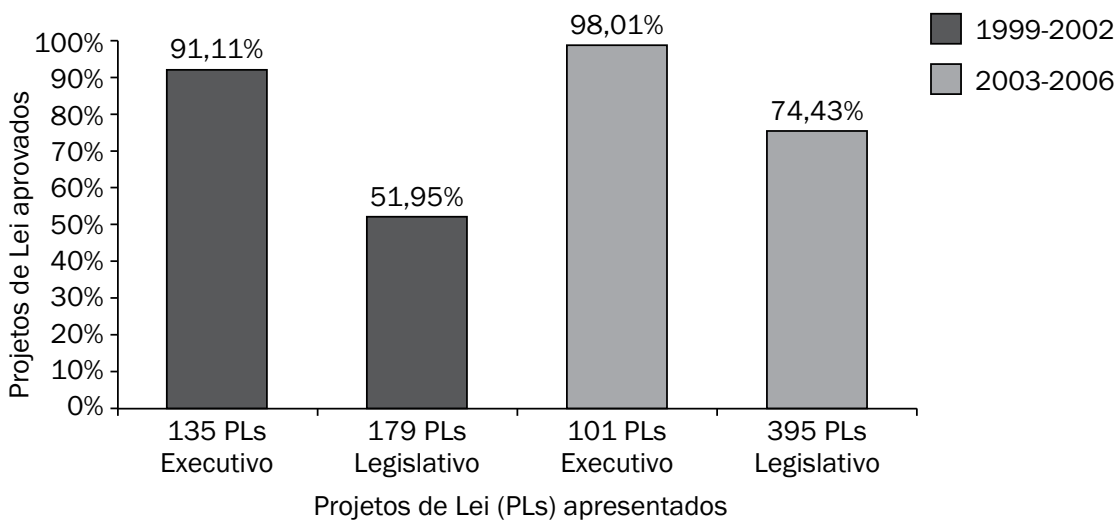

Fonte: Subsecretaria de Atividades Legislativas/ALEAC. Elaborado pelo autor.

Gráfico 1. Percentual de aprovação de projetos de lei em relação ao total de projetos apresentados, por autoria e legislatura.

Em comparação aos dois períodos, observou-se que nos quatro últimos anos analisados o Legislativo aumentou seu percentual de projetos de lei aprovados em relação ao total de proposições apresentadas. Entretanto, apesar do grande número de projetos apresentados pelo Legislativo, foi o Executivo quem teve uma maior efetividade na aprovação das proposições.

Quanto ao tempo de tramitação dos projetos, observou-se que os originados no Executivo receberam um tratamento privilegiado por parte da Assembleia: além de apresentarem índices mais altos de aprovação, também tramitaram mais rapidamente (Tabela 1$)$.

Tabela 1. Projetos de lei aprovados pela Assembleia Legislativa do Estado do Acre segundo o tempo de tramitação (dias), a iniciativa e a legislatura (Acre, 1999-2006).

\begin{tabular}{|c|c|c|c|c|}
\hline \multirow{2}{*}{$\begin{array}{l}\text { Tempo de } \\
\text { tramitação }\end{array}$} & \multicolumn{2}{|c|}{ 1999-2002 } & \multicolumn{2}{|c|}{ 2003-2006 } \\
\hline & Legislativo & Executivo & Legislativo & Executivo \\
\hline 0-15 & 21 & 104 & 102 & 86 \\
\hline $16-30$ & 12 & 6 & 55 & 7 \\
\hline $31-60$ & 17 & 5 & 45 & 4 \\
\hline $61-90$ & 13 & 4 & 29 & 2 \\
\hline $91-120$ & 13 & 2 & 21 & - \\
\hline$>120$ & 17 & 2 & 42 & - \\
\hline Total & 93 & 123 & 294 & 99 \\
\hline Média & 60,2 & 15,4 & 45,9 & 11,5 \\
\hline Moda & $0-15$ & $0-15$ & $0-15$ & $0-15$ \\
\hline
\end{tabular}

Fonte: Subsecretaria de Atividades Legislativas/ALEAC. Elaborado pelo autor. 
O tempo médio de tramitação das proposições de autoria do Executivo foi de 15,4 dias entre 1999 a 2002 e de 11,5 dias entre 2003 a 2006. Já o Legislativo conseguiu aprovar seus projetos no tempo médio de 60,2 dias no período de 1999 a 2002 e, na legislatura seguinte, demorou em média 45,9 dias para aprovar as proposições de sua autoria.

No período de 1999 a 2002, o Executivo aprovou 104 (84,4\%) projetos em no máximo 15 dias, possivelmente recorrendo ao uso do recurso da urgência. De 2003 a 2006, os dados indicaram que tanto o Executivo quanto o Legislativo tiveram grande parte de seus projetos aprovada em até 15 dias (respectivamente $86,8 \%$ e $34,6 \%)$. Todavia, cabe ressaltar que, enquanto o Executivo aprovou todos os seus projetos em no máximo três meses, os parlamentares aprovaram $42(14,2 \%)$ projetos em tempo superior a 120 dias.

\section{Produção legislativa em saúde}

A análise das duas legislaturas mostrou diferenças relevantes. Na primeira (1999 a 2002) houve, por parte dos parlamentares, uma produção envolvendo questões sociais e de cidadania, o que afasta o estigma de que a Assembleia só representou submissão ao governador. Situação diferente foi verificada nos quatro anos seguintes (Tabelas 2 e 3 ).

Tabela 2. Projetos de lei aprovados pela Assembleia Legislativa do Estado do Acre segundo as categorias de classificação (Acre, 1999-2006).

\begin{tabular}{lccccc}
\hline \multirow{2}{*}{ Matéria } & \multicolumn{2}{c}{ 1999-2002 } & & \multicolumn{2}{c}{ 2003-2006 } \\
\cline { 2 - 3 } \cline { 5 - 6 } & Legislativo & Executivo & & Legislativo & Executivo \\
\hline Administração & 3 & 35 & & 25 & 40 \\
Agricultura/Pecuária & 2 & 6 & & - & 1 \\
Cidadania & 23 & 5 & & 15 & 1 \\
Simbólicos & 17 & - & & 25 & - \\
Cultura, Ciência e Tecnologia & 1 & 2 & & 2 & 2 \\
Ecologia & 1 & 1 & & 7 & 4 \\
Economia & - & 24 & & 2 & 11 \\
Fiscalização & 1 & - & & 2 & - \\
Funcionalismo & 6 & 25 & & 1 & 22 \\
Honoríficos & 2 & - & & 181 & - \\
Orçamento & 1 & 11 & & - & 9 \\
Segurança & 3 & 1 & & 3 & - \\
Social & 33 & 13 & 31 & 9 \\
\hline Total & 93 & 123 & 294 & 99 \\
\hline
\end{tabular}

Fonte: Subsecretaria de Atividades Legislativas/ALEAC. Elaborado pelo autor. 
No primeiro período analisado, a agenda do Executivo esteve voltada principalmente para a área da administração, com 35 (28,4\%) projetos aprovados relacionados, especialmente, à organização da máquina pública. Além disso, foram priorizados temas relacionados ao funcionalismo, com aprovação de $25(20,3 \%)$ projetos envolvendo especificamente planos de cargos e salários e abertura de processos seletivos. Nesse período, as questões econômicas, sociais e orçamentárias também estiveram presentes com intensidade na agenda do governador, compreendendo 24 (19,5\%), $13(10,5 \%)$ e $11(8,9 \%)$ projetos aprovados, respectivamente.

No período de 2003 a 2006, a agenda do Executivo não sofreu grandes alterações se comparada com a do período anterior. Proposições relacionadas à administração, ao funcionalismo, à economia, ao orçamento e ao social ainda continuaram em destaque, compreendendo $40(40,4 \%), 22(22,2 \%), 11(11,1 \%)$, nove $(9,0 \%)$ e nove $(9,0 \%)$ projetos aprovados, respectivamente.

Em se tratando do Legislativo, os dados indicaram que na primeira legislatura (1999 a 2002) as leis com natureza social, de cidadania e simbólica assumiram destaque na agenda da Assembleia, compreendendo 33 (35,4\%), 23 (24,7\%) e 17 $(18,2 \%)$ projetos aprovados, respectivamente. Já na segunda legislatura, observou-se que a grande maioria das leis aprovadas foi de natureza honorífica, compreendendo $181(61,5 \%)$ projetos aprovados e restando $31(10,5 \%)$ leis para a área social.

Na categoria "social" estão inclusos os projetos de lei relacionados à temática da saúde, a qual é o objeto deste estudo. Dessa forma, a produção normativa em saúde foi analisada separadamente, sendo os resultados apresentados nas Tabelas 3 e 4 .

Tabela 3. Proposições em saúde aprovadas, segundo ano e autor (Acre, 1999-2006).

\begin{tabular}{lccccc}
\hline \multirow{2}{*}{ Ano } & \multicolumn{2}{c}{ Total de proposições } & & \multicolumn{2}{c}{ Proposições em saúde } \\
\cline { 2 - 3 } \cline { 5 - 6 } & Legislativo & Executivo & & Legislativo & Executivo \\
\hline 1999 & 23 & 32 & & 3 & - \\
2000 & 27 & 26 & & 5 & 1 \\
2001 & 33 & 40 & & 11 & 1 \\
2002 & 10 & 25 & & - & - \\
2003 & 44 & 21 & & 2 & 2 \\
2004 & 47 & 20 & & 5 & - \\
2005 & 100 & 34 & & 12 & - \\
2006 & 103 & 24 & & 1 & - \\
\hline Total & 387 & 222 & 39 & 4 \\
\hline
\end{tabular}

Fonte: Subsecretaria de Atividades Legislativas/ALEAC. Elaborado pelo autor. 
Das 93 matérias de autoria do Legislativo aprovadas entre 1999 a 2002, $20,4 \%$ (19) trataram de temas relacionados à saúde. No período seguinte, das 294 proposições aprovadas, 6,8\% (20) foram relacionadas à saúde. Em se tratando do Executivo, os projetos em saúde corresponderam a 1,6\% (2) e 2,0\% (2) do total aprovado entre 1999-2002 e 2003-2006, respectivamente.

Tabela 4. Categorização das proposições em saúde (Acre, 1999-2006) ${ }^{14}$.

\begin{tabular}{|c|c|c|c|c|}
\hline \multirow{2}{*}{ Matéria } & \multicolumn{2}{|c|}{$1999-2002$} & \multicolumn{2}{|c|}{$2003-2006$} \\
\hline & Legislativo & Executivo & Legislativo & Executivo \\
\hline Administração e planejamento & 4 & 1 & 2 & 1 \\
\hline Alimentação e nutrição & 1 & - & - & - \\
\hline $\begin{array}{l}\text { Medicamentos, vacinas, insumos, } \\
\text { produtos para a saúde }\end{array}$ & 5 & - & 2 & - \\
\hline Políticas, planos, programas e projetos & 2 & 1 & 4 & 1 \\
\hline $\begin{array}{l}\text { Trabalho em saúde } \\
\text { (profissões/profissionais) }\end{array}$ & 1 & - & - & - \\
\hline Saúde bucal & - & - & 1 & - \\
\hline sus & 1 & - & 2 & - \\
\hline $\begin{array}{l}\text { Saúde nos grupos populacionais } \\
\text { específicos }\end{array}$ & 2 & - & 1 & - \\
\hline Criança e Adolescente & - & - & 1 & - \\
\hline Mulher & 1 & - & 3 & - \\
\hline Pessoa com deficiência & - & - & 1 & - \\
\hline DST e Aids & 2 & - & - & - \\
\hline Câncer & - & - & 3 & - \\
\hline Total & 19 & 2 & 20 & 2 \\
\hline
\end{tabular}

Fonte: Adaptado dos estudos de Bem e Vasconcelos. Elaborado pelo autor.

No que compete à natureza dos projetos de lei em saúde, observou-se que o maior número de proposições aprovadas pelos parlamentares no período de 1999 a 2002 esteve relacionado ao assunto "medicamentos, vacinas, insumos, produtos para a saúde 15 ", seguido de "administração e planejamento". Já no período de 2003 a 2006, os assuntos mais presentes foram "políticas, planos, programas e projetos”16.

\footnotetext{
${ }^{14} \mathrm{Com}$ base nas categorias definidas para o Observatório da Saúde no Legislativo, presentes nos estudos de Bem (Observatório da Saúde no Legislativo: as proposições em saúde no âmbito do Congresso Nacional (2011-2012), cit.) e de Vasconcelos.

${ }^{15}$ A exemplo do Projeto de Lei n. 23/2001, que dispôs sobre a adequada destinação a ser dada para medicamentos com prazos de validade vencidos, no âmbito do Estado do Acre.

${ }^{16}$ Pode ser citado o Projeto de Lei n. 15/2004 que dispôs sobre a criação do Programa Estadual para identificação e tratamento da dislexia.
} 
"mulher" e "câncer". No que compete ao Executivo, em ambos os períodos do estudo foram identificados, igualmente, dois projetos relacionados ao tema "administração e planejamento"17, e outros dois referentes às "políticas, planos, programas e projetos"18.

As proposições voltadas para a saúde e de autoria do Executivo foram aprovadas pela Assembleia em menos de 15 dias. Já os projetos de autoria dos parlamentares tiveram tempos diferenciados de tramitação. De 1999 a 2002, 10 projetos dos deputados foram aprovados em menos de dois meses e nove tiveram trâmite superior a esse período. Entre aqueles de tramitação rápida, cita-se o projeto que disciplinou o uso da laqueadura e da vasectomia voluntárias como um dos componentes do planejamento familiar no SUS do Acre ${ }^{19}$, bem como o que instituiu a distribuição gratuita de medicamentos de controle e tratamento de diabetes no âmbito do estado $^{20}$. Entre aqueles que demoraram mais de dois meses para serem aprovados, está o projeto que dispõe sobre a comercialização em farmácias e/ou drogarias dos medicamentos genéricos e que disciplina sua aquisição pelo governo ${ }^{21}$, bem como o que instituiu a distribuição gratuita de medicamentos contra epilepsia no âmbito da Secretaria de Estado de Saúde do Acre ${ }^{22}$.

Na segunda legislatura (2003-2006), apenas um projeto em saúde de autoria dos parlamentares teve tramitação rápida ${ }^{23}$. Os demais (19) tiveram tempo de tramitação que excedeu a dois meses. Entre eles, podem-se citar o que ampliou o mix de produtos comercializados pelas farmácias e drogarias no $\mathrm{Acre}^{24} \mathrm{e}$ o que estabeleceu a obrigatoriedade da realização de cirurgia de redução da mama nos hospitais públicos estaduais, quando indicada para prevenir ou resolver problemas ortopédicos ${ }^{25}$.

Quanto aos projetos de lei em saúde que não foram aprovados, constatou-se que 22 proposições de autoria do Legislativo foram rejeitadas, retiradas, não apreciadas e vetadas, ao longo dos dois períodos estudados. Desses projetos, há o PL n. 34/2000 que dispôs sobre a proibição de depósito prévio (caução) para internação de pacientes em hospitais e clínicas particulares; o PL n. 47/2004 que tratou da obrigatoriedade de todas as farmácias e drogarias a afixarem em local visível a divulgação de listas contendo os genéricos, seus equivalentes e substâncias ativas; e o PL n. 35/2006 que versou sobre a criação do programa de recuperação e recolocação profissional para pessoas portadoras de doenças de alcoolismo e dependência química.

\footnotetext{
${ }^{17}$ Cita-se o Projeto de Lei n. 92/2003 que autorizou o Poder Executivo a ceder, a título oneroso, a tecnologia para fabricação do medicamento benzonidazol.

${ }^{18}$ É o caso do Projeto de Lei n. 61/2000 que instituiu a Política Estadual do Idoso.

${ }^{19}$ Projeto de Lei n. 69/2001.

${ }^{20}$ Projeto de Lei n. 84/2001.

${ }^{21}$ Projeto de Lei n. $75 / 2000$.

${ }^{22}$ Projeto de Lei n. 68/2000.

${ }^{23}$ Projeto de Lei n. 51/2004.

${ }^{24}$ Projeto de Lei n. 56/2006.

${ }^{25}$ Projeto de Lei n. 50/2005.
} 


\section{Os vetos em saúde}

O processo legislativo não se esgota com a apreciação das iniciativas de lei no Plenário da Assembleia. O governador tem assegurado o direito de veto, parcial ou total, sobre boa parte das matérias votadas na Assembleia. Esta, por sua vez, pode derrubar os vetos do governador.

O trâmite das proposições passa por diversas etapas na Assembleia. Esta examina os projetos e decide, por maioria absoluta ou relativa, se aprova, rejeita ou emenda. Se for um projeto do Executivo e tiver recebido emendas, a proposição volta ao governador e este decide se aprova (ou seja, concorda com a emenda), mantém o status quo vetando totalmente o projeto ou modifica o projeto emendado por meio do veto parcial. Posteriormente, cabe ao Legislativo decidir, por maioria absoluta, se derruba o veto. Essa votação é nominal - o que, de fato, expõe os parlamentares. A Constituição do Estado do Acre determina um prazo de 15 dias úteis para o veto total ou parcial do governador. A Assembleia deverá apreciar esse veto em até 30 dias.

Os dois primeiros anos estudados (1999-2000) foram, sem dúvida, períodos nos quais houve o maior número de vetos do Executivo às proposições de autoria dos parlamentares. Ressalta-se o veto ao Projeto de Lei n. 53/1999 porque obrigava a todos os postulantes e ocupantes de cargo de confiança no estado no âmbito dos poderes Executivo, Legislativo e Judiciário, bem como do Ministério Público Estadual e do Tribunal de Contas, a se submeterem a exame antidoping para poderem se manter ou ingressar no cargo. Também merece destaque o veto total ao Projeto de Lei n. 48/2000 que instituía preferencialmente os medicamentos genéricos nas compras efetuadas pelo governo do estado.

Em 2003, registrou-se o veto governamental ao PL n. 04/2003, que dispunha sobre "a realização do exame denominado Emissões Evocadas Otoacústicas nos hospitais da rede pública do Estado do Acre". É importante ressaltar que a Assembleia, durante todo o período estudado, não derrubou os vetos do governador.

\section{Discussão}

Os resultados mostraram que a agenda do Executivo não sofreu grandes alterações se comparados os dois períodos. As proposições aprovadas envolveram, basicamente, questões relacionadas à administração e ao funcionalismo, seguidas por assuntos relacionados à economia, ao orçamento e às questões sociais. Pode-se dizer que o Executivo, nos oito anos do estudo, viu-se na necessidade de apresentar projetos que alteraram significativamente o status quo e, portanto, fez uso de uma agenda pesada ${ }^{26}$.

\footnotetext{
${ }^{26}$ PEREIRA, André Ricardo. Por baixo dos panos: governadores e assembléias no Brasil contemporâneo. 2004. Tese (Doutorado) - Instituto Universitário de Pesquisas do Rio de Janeiro, Universidade Cândido Mendes, Rio de Janeiro, 2004.
} 
Já o Poder Legislativo, na segunda legislatura, fez uso de uma agenda leve ao priorizar questões honoríficas e simbólicas. Essa priorização fica evidente quando se analisam as proposições em saúde apresentadas pelos parlamentares. Mesmo que estas tenham tido números absolutos semelhantes nos dois períodos (foram 19 leis em 1999-2002 e 20 leis em 2003-2006), observa-se uma considerável diferenciação em termos percentuais no âmbito da Assembleia ao se compararem os dois momentos. As leis de natureza honorífica/simbólica de autoria dos parlamentares corresponderam a 70,0\% das leis no período de 2003 a 2006, totalizando 206 proposições aprovadas, ao passo que as matérias em saúde corresponderam a 6,8\% do total aprovado, totalizando 20 proposições. Situação diferente foi verificada no período anterior (19992002), quando $20,4 \%$ do total dos projetos de lei aprovados envolveram a temática da saúde. Dessa forma, o Legislativo deixou de ter uma característica ativa para se tornar reativo ${ }^{27}$, ao priorizar matérias que trataram de homenagens, da instituição de dias, semanas e prêmios, e de declarações de utilidade pública, transferindo ao Executivo a iniciativa das proposições legais mais importantes.

No que compete às questões honoríficas e simbólicas, cabe notar que essas matérias não devem ser fruto de análises precipitadas ${ }^{28,29}$. Se, por um lado, tornar determinada instituição em uma instituição de utilidade pública supõe perdas de receita para o Estado, por outro assegura a existência, em grande medida, de associações criadas de forma espontânea. Quanto às homenagens e denominações dadas aos órgãos públicos, pode-se considerar a natureza eleitoral na adoção de tais medidas. Em outros termos, esse tipo de iniciativa pode ser bastante eficaz do ponto de vista eleitoral, pois, ao se lembrar do nome de uma pessoa ou de uma família tradicional, respeitada pelos moradores, pode-se ter como resultado novos eleitores. Portanto, no estado do Acre, a excessiva quantidade de concessão de títulos de "cidadão acreano" poderia estar visando a uma espécie de negociação política, pelo fato de a concessão de um título a determinada pessoa ou família poder significar benefícios futuros dos mais variados.

Quanto à natureza das matérias de saúde, observou-se um Executivo, nos dois períodos, voltado às questões administrativas e de planejamento, bem como a políticas, planos, programas e projetos. Já o Legislativo manteve-se focado em assuntos relacionados a medicamentos, vacinas, insumos e produtos para a saúde no período de 1999 a 2002; no período seguinte, aprovou mais proposições envolvendo políticas, planos, programas e projetos para a saúde.

\footnotetext{
${ }^{27}$ SANTOS, Fabiano. Democracia, Legislativo e os novos desafios para a expansão do capitalismo brasileiro. Observatório Político Sul-Americano, Rio de Janeiro, 2006.

${ }^{28}$ MORAES, Filomeno. A dinâmica legislativa na Assembléia do Estado do Ceará: 1995 a 1998. In: SANTOS, Fabiano (Org). O Poder Legislativo nos Estados: diversidade e convergência. Rio de Janeiro: Fundação Getúlio Vargas, 2001. p. 189-218.

${ }^{29}$ GROHMANN, Luiz Gustavo Mello. O Veto Presidencial no Brasil: 1946-1964 e 1990-2000. Tese (Doutorado) - Instituto Universitário de Pesquisas do Rio de Janeiro, Universidade Cândido Mendes, Rio de Janeiro, 2003.
} 
Também foi possível identificar um Executivo aprovando em curtos espaços de tempo, tendo poucas dificuldades na condução de sua agenda na Assembleia. Por outro lado, evidenciou-se um Legislativo com menor percentual de projetos de lei aprovados em comparação com o total de proposições enviadas para apreciação -, com tempos de tramitação de seus projetos bem distribuídos. Mesmo o Legislativo apresentando maior quantidade de proposições, em termos percentuais, quem mais aprovou foi o Executivo.

No Executivo, a agenda seguiu um caminho excepcional, quase que exclusivamente em regime de urgência. Portanto, os dados apresentados não harmonizam com a visão de que o chefe do Executivo só vê seus projetos aprovados após excessivas e custosas negociações. Para que isso fosse aplicado à Assembleia Legislativa do Acre, o tempo de tramitação dos projetos do Executivo deveria ser muito maior e a taxa de aprovação não poderia ser tão alta.

Soma-se a isso o fato de grande parte das proposições de autoria do Executivo - incluídas aqui as da saúde - terem sido aprovadas em até dois dias a contar da apresentação na Assembleia, sendo em grande parte ratificadas ainda no mesmo dia em que deram entrada na $\mathrm{Casa}^{30}$. Isso permite considerar o grande poder de agenda que o governador dispunha junto à Assembleia e, de certa forma, justifica o fato de não serem utilizadas as Medidas Provisórias, instrumento previsto na Constituição Estadual.

Por outro lado, os curtos prazos de apreciação na Assembleia das matérias propostas pelo Executivo podem representar a existência de negociações envolvendo os dois poderes na etapa da elaboração dos projetos. Tendo esse argumento como base, pode-se dizer que a rápida aprovação das matérias seria, portanto, apenas a confirmação de acordos anteriormente estabelecidos ${ }^{31}$.

Nessa questão, é importante ressaltar o processo de negociação da política realizado nos bastidores, que vai além dos regimentos institucionais e que envolve um jogo de forças e poder que se apresenta não apenas na esfera do Legislativo, mas também fora dela. Esse processo precisa ser compreendido para se entenderem as opções políticas, as quais envolvem um jogo que tem início antes mesmo da elaboração das proposições e em que estão presentes interesses de diversos grupos - a exemplo dos lobbies das indústrias de equipamentos e medicamentos, dos prestadores de serviço da saúde, das corporações profissionais, dos planos e seguros de saúde ${ }^{32}$.

\footnotetext{
${ }^{30} \mathrm{Em}$ estudo sobre a produção legislativa em saúde aprovada no período de 1990 a 2004 e as principais características e especificidades da relação Executivo-Legislativo na definição da política pública de saúde brasileira, Baptista e Machado (2007) identificaram que os projetos em saúde de autoria do Executivo tramitaram cinco vezes mais rapidamente em comparação aos projetos do Legislativo. BAPTISTA, Tatiana W. de Faria; MACHADO, Cristiani Vieira, op. cit.

${ }^{31}$ BAPTISTA, Tatiana W. de Faria. Análise da produção legislativa em saúde no Congresso Nacional brasileiro (1990-2006). Rio de Janeiro: Cad. Saúde Pública, v. 26, p. 97-109, 2010. http://dx.doi.org/10.1590/ S0102-311X2010000100011.

${ }^{32}$ BAPTISTA, Tatiana W. de Faria; MACHADO, Cristiani Vieira, op. cit.
} 
Entende-se que uma das alternativas para o governador conseguir obter altas taxas de sucesso em suas proposições seria adotar a estratégia de conquistar o apoio parlamentar caso a caso, por meio da pressão sobre as bases dos deputados. Como observado, o Executivo conseguiu implementar sua agenda em face de um Legislativo disposto a cooperar, mas que, mesmo assim, não deixou de propor matérias. Nesse sentido, o esforço por parte do Executivo em encaminhar projetos ao Legislativo pode ser parte de uma estratégia na qual aprová-los pode não ser necessariamente o objetivo principal ${ }^{33}$.

O direito de requerer urgência para seus projetos confere ao chefe do Executivo a redução do tempo da atividade parlamentar. Os projetos com tramitação em regime de urgência significam que o pronunciamento do parlamento sobre determinada matéria deve ser feito em um prazo estipulado legalmente, independentemente de sua complexidade e do número de interesses envolvidos. Além disso, quanto maior o tempo destinado em Plenário para as matérias do Executivo, menor é o tempo livre para a Assembleia considerar as matérias originadas na própria casa ${ }^{34}$.

Os vetos também sugerem relações entre os poderes. Se usados de forma intensa, podem indicar a existência seja de um conflito de preferências políticas entre Executivo e Legislativo, seja de uma disputa de competência entre os dois poderes. Na primeira legislatura estudada, sugere-se que o governador, por representar a mudança em relação aos moldes políticos anteriores, teria encontrado mais resistência em aprovar seus projetos no Legislativo.

Por outro lado, o uso pouco intenso do veto sugere uma coincidência de preferências políticas entre a maioria dos deputados e o governador, ou mesmo um alto grau de consenso entre os dois poderes quanto à jurisdição de cada um na produção de legislação. O governador, para obter sucesso, precisa contar com uma ampla maioria na Assembleia - formando uma coalizão de governo, considerada um pré-requisito para uma menor quantidade de vetos e derrubadas ${ }^{35}$. Dessa maneira, entende-se que quanto mais apoio tem o governador, menor será a quantidade de vetos necessários para barrar projetos que não estão dentro de sua preferência, pela simples razão de que não seria emitida uma grande quantidade de projetos muito distantes do interesse do Executivo.

Nesse sentido, torna-se importante ressaltar o papel desempenhado pela Mesa Diretora e pelas lideranças partidárias, as quais decidem sobre a agilidade de uma matéria e, muitas vezes, utilizam todos os instrumentos de obstrução para

\footnotetext{
${ }^{33} \mathrm{DINIZ}$, Simone. Interações entre os poderes Executivo e Legislativo no processo decisório: avaliando sucesso e fracasso presidencial. Dados Rev. Ciênc. Soc., v. 48, n. 2, p. 333-369, 2005. http://dx.doi.org/10.1590/S0011-52582005000200004.

${ }^{34}$ SANTOS, Fabiano. Instituições eleitorais e desempenho do presidencialismo no Brasil. Dados Rev. Ciênc Soc., v. 42, n. 1, p. 111-138, 1999. http://dx.doi.org/10.1590/S0011-52581999000100006.

${ }^{35}$ GROHMANN, Luiz Gustavo Mello. op. cit.
} 
adiar a apreciação de outras. As lideranças também podem pedir urgência para a tramitação de determinados projetos. Por outro lado, cabe ao Executivo o direito de não somente requerer unilateralmente urgência para a consideração de suas proposições, mas também tratar com exclusividade de matéria orçamentária e tributária.

No decorrer do texto, enfatizou-se que 50,0\% dos parlamentares eleitos em 1998 compuseram a frente formal de apoio ao governador e que, nas eleições de 2002, os partidos da FPA conquistaram 54,0\% das cadeiras na Assembleia. Nesse cenário, ter pouco mais da metade das cadeiras em mãos da base aliada não significaria, necessariamente, a certeza da aprovação dos projetos de interesse do governo.

Poder-se-ia dizer, nessa perspectiva, que os deputados estaduais eleitos pelo mesmo partido do governador teriam assumido a condição de governistas. $\mathrm{O}$ mesmo se diria em relação àqueles que pertenciam aos partidos que fizeram parte da coligação eleitoral de apoio ao governador. No entanto, esse critério pode ser falho. É possível que os parlamentares do mesmo partido do governador ou da coligação não sejam, de fato, aliados. Membros de legendas não coligadas também podem não ser necessariamente adversários do governo ${ }^{36}$.

Nesse sentido, é fundamental considerar que o parlamentar não é obrigado a observar a posição de preferência do Executivo, a não ser que tenha ganhos consideráveis com a aprovação de um projeto e que os custos dessa aprovação não sejam maiores do que os ganhos ${ }^{37}$.

Há de se dizer, contudo, que a formação de maiorias em Plenário obedece a uma lógica que vai além do Legislativo. Como ator político relevante, o governador encaminha demandas à consideração dos legisladores, na espera de que sua base partidária aprove as políticas que lhe interessam. Para conseguir aprovar suas proposições, o Executivo dispõe de recursos políticos e materiais distintos dos que são controlados pelo eleitorado, pelos grupos organizados e pelos militantes partidários. Entre esses recursos, desponta o domínio exercido pelo governador sobre a elaboração da agenda legislativa ${ }^{38}$.

Para que se possa entender a intensidade desse domínio sobre a agenda legislativa, é importante que se façam algumas ponderações. Uma delas refere-se a como se encontram distribuídos, entre os poderes, os direitos legislativos formais. Uma segunda observação refere-se a como os direitos legislativos da Assembleia se encontram distribuídos no interior de sua estrutura formal de controle, a citar, a Mesa Diretora, as comissões permanentes e os parlamentares, vistos individualmente. E, por fim, importa examinar a força das lideranças partidárias existentes no interior da Assembleia ${ }^{39}$.

\footnotetext{
${ }^{36}$ PEREIRA, André Ricardo. op. cit.

${ }^{37}$ GROHMANN, Luiz Gustavo Mello. op. cit.

${ }^{38}$ SANTOS, Fabiano (Org.). O Poder Legislativo nos Estados: diversidade e convergência. Rio de Janeiro: Fundação Getúlio Vargas, 2001.

${ }^{39}$ Id. Ibid.
} 
É possível, mesmo que se adote um sistema presidencialista de governo e um sistema eleitoral proporcional - e, portanto, se opte pela distribuição do poder político entre vários atores -, haver a transferência do controle da agenda legislativa a um número reduzido de líderes, tais como o presidente e a liderança do partido. Nessa situação, embora a formação da pólis obedeça a uma perspectiva de pesos e contrapesos, o processo de tomada de decisões segue a concepção de concentração de poder. Nesse sentido, o sucesso do governador deve-se ao fato de ele saber se organizar com a Assembleia ${ }^{40}$.

Nessa lógica, ter aliados à frente da Mesa Diretora e das comissões permanentes pode significar a manutenção do controle político da Assembleia. Foi o que se observou por meio da distribuição dos cargos considerados mais estratégicos no interior da Assembleia, os quais ficaram sob o comando de aliados do governo. Desse modo, o chefe do Executivo buscou governar com os partidos que compuseram a sua frente de apoio, com o propósito de contemplá-los nos espaços institucionais, visando à governabilidade e à manutenção da coalizão. Pode-se sugerir que essa composição iniciada em 1999 consolida-se na legislatura seguinte e tem como consequência um chefe do Executivo com amplos poderes de agenda. Nesse cenário, os parlamentares, especialmente na segunda legislatura, passam a priorizar uma agenda na qual a saúde deixa, percentualmente, de ser um tema prioritário.

Os dados apresentados remetem à necessidade de estudos mais detalhados sobre a relação entre Executivo e Legislativo no Acre e sua conexão com a definição de políticas para a saúde, de modo a melhor compreender a dinâmica do processo decisório e de definição de prioridades. Pode-se extrair, corroborando com os estudos em nível nacional, que o processo político encontra-se desbalanceado, com um Executivo que concentra poder no âmbito da Assembleia e que assume um importante papel na definição de propostas políticas.

\section{Referências}

ABRANCHES, Sérgio Henrique H. de. Presidencialismo de coalizão: o dilema institucional brasileiro. Dados Rev. Ciênc Soc., v. 31, p. 5-34, 1988.

ABRUCIO, Fernando Luiz. Os barões da federação: os governadores e a redemocratização brasileira. 2. ed. São Paulo: Hucitec, 2002.

TEIXEIRA, M. A. C.; COSTA, V. M. F. O Papel Institucional da Assembléia Legislativa Paulista: 1995 a 1998. In: SANTOS, Fabiano (Org.). O Poder Legislativo nos Estados: diversidade e convergência. Rio de Janeiro: Fundação Getúlio Vargas, 2001. p. 219-246.

ANASTASIA, Fátima. Transformando o Legislativo: a experiência da Assembléia Legislativa de Minas Gerais. In: SANTOS, Fabiano (Org.). O Poder Legislativo nos Estados: diversidade e convergência. Rio de Janeiro: Fundação Getúlio Vargas, 2001. p. 23-83.

${ }^{40}$ SANTOS, Fabiano. O Poder Legislativo no Presidencialismo de coalizão, cit. 
BAPTISTA, Tatiana W. de Faria. Análise da produção legislativa em saúde no Congresso Nacional brasileiro (1990-2006). Rio de Janeiro: Cad. Saúde Pública, v. 26, p. 97-109, 2010. http://dx.doi.org/10.1590/S0102-311X2010000100011.

BAPTISTA, Tatiana W. de Faria; MACHADO, Cristiani Vieira. O Legislativo e a Saúde no Brasil. In: MATTA, Gustavo Corrêa; PONTES, Ana Lúcia de Moura (Orgs.). Políticas de saúde: organização e operacionalização do sistema único de saúde. Rio de Janeiro: EPSJV / Fiocruz, 2007. p. 81-113.

BEM, Pricken de. Observatório da Saúde no Legislativo: as proposições em saúde no âmbito do Congresso Nacional (2011- 2012). Universidade de Brasília (UnB): Tempus-Actas de Saúde Coletiva, v. 7, n. 1, p. 107-114, 2013.

DINIZ, Simone. Interações entre os poderes Executivo e Legislativo no processo decisório: avaliando sucesso e fracasso presidencial. Dados Rev. Ciênc. Soc., v. 48, n. 2, p. 333-69, 2005. http://dx.doi.org/10.1590/S0011-52582005000200004.

DOMINGUES, Mauro Petersem. Espírito Santo: produção legal e relações entre os poderes Executivo e Legislativo entre 1995 e 1998. In: SANTOS, Fabiano (Org.). O Poder Legislativo nos Estados: diversidade e convergência. Rio de Janeiro: Fundação Getúlio Vargas, 2001.p. 85-111.

ESTADO DO ACRE. Subsecretaria de Atividades Legislativas. Rio Branco: Assembleia Legislativa do Estado do Acre, 2008.

FIGUEIREDO, Argelina Cheibub. LIMONGI, Fernando. Executivo e Legislativo na nova ordem constitucional. 2. ed., Rio de Janeiro: Ed. FGV, 2001.

GROHMANN, Luiz Gustavo Mello. O Veto Presidencial no Brasil: 1946-1964 e 1990-2000. Tese (Doutorado) - Instituto Universitário de Pesquisas do Rio de Janeiro, Universidade Cândido Mendes, Rio de Janeiro, 2003.

MORAES, Filomeno. A Dinâmica Legislativa na Assembléia do Estado do Ceará: 1995 a 1998. In: SANTOS, Fabiano (Org). O Poder Legislativo nos Estados: diversidade e convergência. Rio de Janeiro: Fundação Getúlio Vargas, p. 189-218. 2001.

PEREIRA, André Ricardo. Por Baixo dos Panos: Governadores e Assembléias no Brasil contemporâneo. 2004. Tese (Doutorado) - Instituto Universitário de Pesquisas do Rio de Janeiro, Universidade Cândido Mendes, Rio de Janeiro, 2004.

SANTOS, Fabiano. A dinâmica legislativa no Estado do Rio de Janeiro: análise de uma legislatura. In: SANTOS, Fabiano (Org). O Poder Legislativo nos Estados: diversidade e convergência. Rio de Janeiro: Fundação Getúlio Vargas, 2001. p. 163-87.

. Democracia, Legislativo e os novos desafios para a expansão do capitalismo brasileiro. Observatório Político Sul-Americano, Rio de Janeiro, 2006.

. Instituições eleitorais e desempenho do presidencialismo no Brasil. Dados Rev. Ciênc Soc., v. 42, n. 1, p. 111-38, 1999. http://dx.doi.org/10.1590/S0011-52581999000100006. 
SANTOS, Fabiano. O Poder Legislativo no Presidencialismo de Coalizão. Belo Horizonte: Ed. da UFMG; Rio de Janeiro: IUPERJ, 2003.

O Poder Legislativo nos Estados: diversidade e convergência. Rio de Janeiro: Fundação Getúlio Vargas, 2001.

VASCONCELOS, Wagner R. Manso de. Observatório da saúde no legislativo: informação e comunicação a serviço da participação social em saúde. 2009. Dissertação (Mestrado), Universidade de Brasília, Brasília, 2009.

VIANA, Ana Luiza d’Ávila et al. Política de saúde e eqüidade. São Paulo em Perspectiva, São Paulo, v. 17, n. 1, p. 58-68. http://dx.doi.org/10.1590/S0102-88392003000100007.

Luci Maria Teston - Doutoranda em Saúde Pública pela Faculdade de Saúde Pública da Universidade de São Paulo; mestre em Ciência Política pelo Instituto Universitário de Pesquisas do Rio de Janeiro. Professora da Universidade Federal do Acre. Rio Branco/AC, Brasil.E-mail: luci_teston@hotmail.com. 